\title{
Avaliação da germinação de milho e feijão sob efeito de biofertilizantes
}

\section{Larissa Maria Vaso ${ }^{1}$, Gislayne de Araujo Bitencourt ${ }^{2}$, Natália da Silva Guidorissi ${ }^{3}$ e Jaine Pereira Flores ${ }^{3}$}

\author{
${ }^{1}$ Instituto Agronômico de Campinas. Centro de Solos. Programa de Pós-Graduação \\ em Agricultura Tropical e Subtropical. Av. Barão de Itapura, 1481. Campinas-SP, \\ Brasil (CEP 13075-630). E-mail: larissamvaso@gmail.com. \\ ${ }^{2}$ Instituto Federal de Educação, Ciência e Tecnologia de São Paulo. Campus \\ Avançado de Tupã. Avenida do Universitário, 145. Jardim Ipiranga. Tupã-SP, Brasil \\ (CEP 17607-220). \\ ${ }^{3}$ Universidade Estadual de Mato Grosso do Sul. Curso de Graduação em Agronomia. \\ Campus de Aquidauana. Rodovia Aquidauana-UEMS, km 12. Aquidauana-MS, Brasil \\ (CEP 79200-000).
}

Resumo. Os biofertilizantes de origem animal, apresentam alto teor de nutrientes que possibilitam seu uso na adubação vegetal. No entanto, para ser utilizado é necessária sua caracterização química, pois podem apresentar efeitos indesejados de toxicidade para o solo e plantas. Objetivou-se com o presente trabalho, avaliar o efeito de dois biofertilizantes (bovino e ovino) sobre a germinação e crescimento inicial de milho e feijão por meio de teste ecotoxicológico. Os biofertilizantes bovino e ovino foram diluídos utilizando água deionizada nas concentrações de: 0, 150, 300,450 e $600 \mathrm{~mL} . \mathrm{L}^{-1}$. As caixas tipo gerbox foram forradas com papel de filtro umedecido com $7 \mathrm{~mL}$ de solução de biofertilizante e 18 sementes foram distribuídas em cada caixa, onde permaneceram em câmara de crescimento a $25^{\circ} \mathrm{C}$, com fotoperíodo de $12 \mathrm{~h}$, por cinco dias. 0 delineamento utilizado foi inteiramente casualizado (DIC) em fatorial $2 \times 5$ (biofertilizantes $\mathrm{x}$ concentrações) com três repetições. As variáveis avaliadas foram: porcentagem de germinação, comprimento de raiz e de parte aérea. Os dados foram submetidos a análise de variância e teste de Tukey a $5 \%$ de probabilidade. 0 aumento no comprimento de raiz de milho foi verificado em ambos os biofertilizantes na concentração de $150 \mathrm{~mL} \cdot \mathrm{L}^{-1}$. A concentração de 600 mL. $\mathrm{L}^{-1}$ do biofertilizante bovino promoveu maior porcentagem da germinação de feijão comparado ao ovino. Porém, os maiores valores de comprimento de parte aérea e de raiz foram observados no ovino para a mesma concentração. Os biofertilizantes não apresentaram efeitos tóxicos na germinação e crescimento de ambas as espécies.
Recebido

$26 / 01 / 2021$

Aceito

$15 / 04 / 2021$

Disponível on line $26 / 04 / 2021$

Publicado

$30 / 04 / 2021$

Acesso aberto

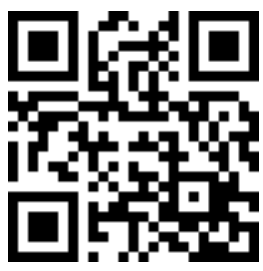

ORCIO

(D) 0000-0003-0027-6106 Larissa Maria Vaso 
Palavras-chave: Adubo; Bioensaio; Dejetos animais; Fertilizante orgânico.

\begin{abstract}
Evaluation on the germination in corn and beans under the effect of biofertilizers. Animal waste biofertilizers have a high content of nutrients that enable their use in plant fertilization. However, to be used it is necessary to characterize it chemically, as they may have undesired toxicity effects for the soil and plants. The objective of this work was evaluated the effect of two biofertilizers (bovine and sheep) on the germination and initial growth of corn and bean through ecotoxicological testing. The bovine and sheep biofertilizers were diluted using deionized water in the concentrations of $0,150,300,450$ and $600 \mathrm{~mL} \cdot \mathrm{L}^{-1}$. The gerbox boxes were lined with filter paper moistened with $7 \mathrm{~mL}$ of biofertilizer solution and 18 seeds were distributed in each box, where they remained in a growth chamber at $25{ }^{\circ} \mathrm{C}$, with a photoperiod of $12 \mathrm{~h}$, for five days. The design was used completely randomized (DIC) in factorial $2 \times 5$ (biofertilizers $\mathrm{x}$ concentrations) with three replications. The variables were evaluated, germination percentage, root and shoot length. The data were submitted to analysis of variance and Tukey's test at $5 \%$ probability. The increase in the length of corn root was observed in both biofertilizers at a concentration of $150 \mathrm{~mL} . \mathrm{L}^{-1}$. The concentration of $600 \mathrm{~mL} \cdot \mathrm{L}^{-1}$ of bovine biofertilizer promoted a higher percentage of bean germination compared to sheep. However, the highest values of shoot and root length were observed in the sheep for the same concentration. Biofertilizers did not show toxic effects on the germination and growth of both species.
\end{abstract}

Keywords: Fertilizer; Bioassay; Animal waste; Organic fertilizer.
D) $0000-0001-7215-1754$

Gislayne de Araujo

Bitencourt

(1) 0000-0001-8037-1933

Natália da Silva

Guidorissi

D) 0000-0002-9621-6230

Jaine Pereira Flores

\section{Introdução}

Encontrar sistemas que sejam capazes de conciliar a produção agropecuária, ponderando o uso dos recursos naturais, de modo que, priorize a preservação ambiental é o grande desafio do agronegócio (Sá et al., 2015). Uma das possibilidades de integrar esse sistema, é a aplicação de água residuária em culturas de interesse agrícola, oriunda da disposição final do tratamento de resíduos e, assim, contribuir para a redução da poluição ambiental, mitigação dos dejetos provenientes da pecuária e consequentemente, melhorar as características físico-químicas do solo (Aguiar et al., 2017; Nascentes et al., 2019).

Na busca por uma produção sustentável, na síntese do biofertilizante vem sendo realizada a partir da fermentação anaeróbica de dejetos animais por meio de biodigestores. Esse subproduto é um liquido composto por elevada concentração de matéria orgânica; auxilia a multiplicação de microrganismos benéficos; melhoram a porosidade do solo, permitindo maior aeração em camadas mais profundas, propiciando um maior desenvolvimento das plantas bem como substitui a adubação química, reduzindo os custos e sendo um aliado na conservação ambiental (Martins et al., 2015; Aguiar et al., 2017).

Entretanto, a utilização de água residuária na agricultura, ainda é realizada sem embasamento técnico, o que pode acarretar na contaminação de águas subterrâneas e 
causar desequilíbrios na relação solo-planta. Nesse contexto, é imprescindível o conhecimento das características físicas, químicas, biológicas e toxicológicas dos biofertilizantes, para que os mesmos possam ser utilizados com segurança e não causem impactos negativos (Silva et al., 2015; Barszcz et al., 2019).

Neste cenário, os testes ecotoxicológicos utilizando diferentes espécies podem contribuir para a identificação do potencial de contaminação destes resíduos, incluindo efluentes têxteis e agroquímicos, principalmente quando os mesmos forem descartados incorretamente. Os biotestes com plantas fundamentam-se na grande variedade de parâmetros avaliados, tais como, germinação, ganho de biomassa, crescimento de raiz e aéreo, além de apresentarem baixo custo e podem ser realizados em qualquer época do ano (Franco et al., 2017).

Em vista disso a porcentagem de germinação de espécies sensíveis, na presença de contaminantes potencialmente tóxicos, possa ser utilizado como um indicador do grau de toxidez. Dentre as culturas que podem ser beneficiadas pelo uso de biofertilizantes encontram-se o milho (Zea mays L.) e o feijão (Phaseolus vulgaris L.), são espécies amplamente utilizadas em testes ecotoxicológicos, por serem internacionalmente padronizadas, são úteis na avaliação da toxicidade, por apresentarem germinação rápida e uniforme, além de expressarem resultados em baixas concentrações de substâncias tóxicas (ISO, 2014; Bitencourt et al., 2020).

Nesse sentido, os ensaios de germinação de sementes e crescimento de plantas, são os caracteres mais utilizados para avaliar a toxicidade de um composto e o potencial de contaminação desses resíduos. Em vista disso, o presente trabalho teve como objetivo avaliar o efeito de dois biofertilizantes (bovino e ovino) sobre a germinação e crescimento inicial de sementes de milho e feijão por meio de teste ecotoxicológico.

\section{Material e métodos}

Os experimentos foram realizados no laboratório de Fitossanidade, da Universidade Estadual de Mato Grosso do Sul (UEMS), Unidade Universitária de Aquidauana. Os biofertilizantes bovino e ovino foram cedidos pelo Laboratório de Tratamento de Resíduos da mesma unidade.

Os biofertilizantes foram produzidos utilizando biodigestores tipo batelada, com capacidade de 2 litros de substrato em fermentação. Os mesmos, foram abastecidos com água + dejetos contendo aproximadamente $6 \%$ (m:v), sólidos totais sendo operado com TRH (tempo de retenção hidráulica) de 90 dias em condições anaeróbias.

Foi aferido o $\mathrm{pH}$ e a condutividade elétrica dos dois biofertilizantes com o auxílio de um pHmetro e condutivímetro conforme metodologia proposta por (Abreu et al., 2009).

A quantificação de nitrogênio foi realizada de acordo com o método de digestão com $\mathrm{H}_{2} \mathrm{SO}_{4}+\mathrm{H}_{2} \mathrm{O}_{2}$ e destilação de Kjeldahl conforme metodologia descrita por Miyazama et al. (2009) e de fósforo disponível de acordo com o método de Mehlich 1, a leitura foi realizada utilizando um espectrofotômetro no comprimento de onda de $660 \mathrm{~nm}$ de acordo com a metodologia proposta por Silva et al. (2009). A matéria orgânica foi quantificada com base no método de Walkley-Black segundo (Embrapa, 1997).

Os coliformes totais e termotolerantes foram quantificados por meio do teste de tubo múltiplo conforme (Soares e Maia, 1999).

Os biofertilizantes foram diluídos em água deionizada nas concentrações: 0 (água deionizada), 150, 300, 450 e $600 \mathrm{~mL} \mathrm{~L}^{-1}$ para cada biofertilizante.

O bioensaio de germinação foi baseado na normativa ISO 11269-2 (ISO, 2014), realizado com duas espécies padronizadas, sendo elas: Zea mays L., milho híbrido MG600PW Grow AgroSciences e Phaseolus vulgaris L., feijão carioca BRS ESTILO. 
As sementes foram distribuídas em três fileiras de seis, totalizando 18 sementes em cada caixa gerbox, sendo considerada cada caixa uma parcela, tendo papel filtro como substrato umedecido com $7 \mathrm{~mL}$ de biofertilizante nas cinco concentrações citadas acima.

0 delineamento experimental utilizado foi inteiramente casualizado em esquema fatorial 2x5 (dois biofertilizantes e cinco concentrações) com três repetições, totalizando 30 parcelas experimentais, para cada espécie.

As caixas gerbox foram mantidas em câmara de crescimento do tipo BOD com temperatura controlada $25{ }^{\circ} \mathrm{C} \pm 2{ }^{\circ} \mathrm{C}$ e fotoperíodo de $12 \mathrm{~h}$, por um período de cinco dias. Ao final do experimento, foram determinadas a porcentagem de germinação, comprimento de raiz (CR) e de parte aérea das plântulas (CPA). A porcentagem de germinação foi calculada com base no número de sementes que emitiram radícula com no mínimo $2 \mathrm{~mm}$. O comprimento de raiz e parte aérea foi mensurado utilizando paquímetro digital.

Os dados obtidos foram submetidos a análise de variância (teste F) e as médias foram comparadas por meio do teste de Tukey $(\mathrm{p}<0,05)$, utilizando o programa estatístico SISVAR (Ferreira, 2019).

\section{Resultados e discussão}

Na Tabela 1 estão apresentados os parâmetros químicos dos dois biofertilizantes utilizados no experimento: $\mathrm{pH}$, condutividade elétrica, nitrogênio, fósforo, matéria orgânica e, coliformes totais e termotolerantes.

Tabela 1. Caracterização dos parâmetros químicos dos dois biofertilizantes.

\begin{tabular}{|c|c|c|c|c|c|c|c|}
\hline & pH & $\begin{array}{c}\mathrm{CE} \\
(\mathrm{mS} \mathrm{cm}-1)\end{array}$ & $\begin{array}{c}\mathrm{N} \\
\left(\mathrm{g} \mathrm{kg}^{-1}\right)\end{array}$ & $\begin{array}{c}P \\
\left(\mathrm{mg} \mathrm{dm}^{-3}\right)\end{array}$ & $\begin{array}{c}\text { MO } \\
\left(\mathrm{g} \mathrm{kg}^{-1}\right)\end{array}$ & $\begin{array}{l}\text { CTO } \\
(\mathrm{mL})\end{array}$ & $\begin{array}{c}\text { CTE } \\
(\mathrm{mL})\end{array}$ \\
\hline Bovino & 8,57 & 6,83 & 22,89 & 175,01 & 28,19 & $2,5.10^{-2}$ & $0,4 \cdot 10^{-2}$ \\
\hline Ovino & 8,10 & 2,60 & 24,08 & 38,54 & 28,19 & $1,5.10^{-2}$ & $0,3 \cdot 10^{-2}$ \\
\hline
\end{tabular}

$\mathrm{CE}$ = condutividade elétrica; $\mathrm{N}=$ nitrogênio; $\mathrm{P}=$ fósforo disponível; $\mathrm{MO}=$ matéria orgânica; CTO = coliformes totais; CTE = coliformes termotolerantes.

Analisando a magnitude dos dados, o pH alcalino dos biofertilizantes estão dentro da faixa de $\mathrm{pH}$ recomendada conforme às exigências biológicas sugeridas pela Resolução CONAMA no 430/2011 (Brasil, 2011), que define como aceitável o pH entre 5 e 9 para efluentes. Em condições de introdução de material orgânico na forma de solução nutritiva o pH de 5,5 a 6,5 é o mais aconselhado para garantir a disponibilidade de nutrientes para as plantas. Contudo, em condições de solo, o intervalo recomendado é de 5,5 a 6,5 (Brito et al., 2017).

O pH alcalino acarreta no excesso de sais solúveis, sódio trocável ou ambos, que interferem no desenvolvimento da planta. 0 efeito mais recorrente do excesso de salinidade nas plantas é a redução do crescimento devido a desequilíbrios nutricionais (Thode Filho et al., 2019).

A condutividade elétrica, estima a quantidade de sais contidos em uma solução, os resultados demonstraram valores acima da faixa recomendada $\left(\leq 1 \mathrm{mS} \mathrm{cm}^{-1}\right)$ em ambos os biofertilizantes, sendo $6,83 \mathrm{mS} \mathrm{cm}^{-1}$ no bovino e de $2,60 \mathrm{mS} \mathrm{cm}^{-1}$ no ovino. Valores entre 2 e $4 \mathrm{mS} \mathrm{cm}^{-1}$ são considerados toleráveis, apenas espécies muito sensíveis são afetadas. No entanto, a faixa de 4 a $8 \mathrm{mS} \mathrm{cm}^{-1}$ é considerada moderada, podendo reduzir a produtividade na maioria das culturas. Valores de 8 a $16 \mathrm{mS} \mathrm{cm}^{-1}$ são considerados altos, indicando tolerância a salinidade pelas plantas. 0 milho e o feijão são considerados 
espécies sensíveis a salinidade, valores acima de $1,0 \mathrm{mS} \mathrm{cm}^{-1}$ interferem na performance reduzindo a produtividade (Soares Filho et al., 2016).

Conforme as diretrizes contidas na Resolução CONAMA no 375/2006 do (Brasil, 2006) levando em consideração dados para lodo de esgoto, os biofertilizantes foram classificados como tipo A, sendo o número de patógenos é menor que $<10^{3} \mathrm{NMP} / \mathrm{g}$ de $\mathrm{ST}$, assim, permitido seu uso não oferecendo riscos ao meio ambiente. As quantificações de coliformes totais e termotolerantes estão apresentados na tabela acima (Tabela 1).

Os teores de nitrogênio $(\mathrm{N})$, fósforo $(\mathrm{P})$ e matéria orgânica (MO). Não há faixas recomendadas para o reuso do efluente na agricultura, pois, as culturas possuem exigências diferentes. Entretanto, o material digerido no biodigestor supre várias necessidades das culturas, sendo uma alternativa de fonte nutricional. Quando o mesmo aplicado diretamente ao solo, ele tende a proporcionar uma melhor estruturação do solo; melhora da atividade microbiológica, maior retenção de umidade, fornecimento de nutrientes minerais como nitrogênio $(\mathrm{N})$, fósforo $(\mathrm{P})$ e potássio $(\mathrm{K})$, consequentemente melhorando a fertilidade do solo (Alencar et al., 2015; Matos et al., 2018). 0 biofertilizante bovino apresentou elevada concentração de $\mathrm{P}$, quando comparado ao biofertilizante ovino.

Verificou-se na Tabela 2 nas variáveis porcentagem de germinação (G\%) e comprimento de parte aérea (CPA) em ambas as espécies que não houve diferenças significativas nas fontes variáveis de concentração e biofertilizante. Ainda na Tabela 2, foi verificada diferença significativa $(\mathrm{p}<0,05)$ para concentração de biofertilizante na variável comprimento de raiz (CR) de milho.

Na interação entre concentração x biofertilizante para a variável porcentagem de germinação em feijão houve significância (Tabela 2). Essa diferença de germinação entre as espécies pode ser explicada devido aos diferentes substratos utilizados, nesse caso, os biofertilizantes foram aplicados em papel de filtro, mantendo-se em contanto direto com as sementes. Outro aspecto, é com relação a espécie avaliada e, qual o estágio de desenvolvimento em que o estresse é aplicado (Bitencourt et al., 2020). Segundo Soares Filho et al. (2016), ressalta que o crescimento inicial é bastante sensível ao excesso de sais, e a resposta pode variar conforme a tolerância da espécie, genótipo, estágio fenológico e o tempo de exposição.

Tabela 2. Valores dos quadrados médio para as características de porcentagem de germinação; comprimento da parte aérea (CPA) e de raiz (CR), de Zea mays L. (milho) e Phaseolus vulgaris L. (feijão) submetidas a diferentes concentrações $\left(0,150,300,450,600 \mathrm{~mL} \mathrm{~L}^{-1}\right)$ de dois biofertilizantes.

\begin{tabular}{|l|c|c|c|c|c|c|c|}
\hline \multirow{2}{*}{ FV } & \multirow{2}{*}{ GL } & \multicolumn{2}{|c|}{ Germinação (\%) } & \multicolumn{2}{c|}{ CPA (mm) } & \multicolumn{2}{c|}{ CR (mm) } \\
\cline { 3 - 8 } & & Milho & Feijão & Milho & Feijão & Milho & Feijão \\
\hline Concentração & 4 & 4,12 & 242,72 & 0,006 & 191,8 & $21,69^{*}$ & 317,53 \\
\hline Biofertilizante & 1 & 55,54 & 25,70 & 0,453 & 1434,2 & 5,18 & 2074,17 \\
\hline Conc. x Bio. & 4 & 55,52 & $570,97^{*}$ & 0,158 & 254,0 & 3,32 & 327,77 \\
\hline Erro & 20 & & & & & & \\
\hline
\end{tabular}

*Significativo $(p<0,05)$. Legenda: $\mathrm{FV}=$ fonte de variação; $\mathrm{GL}=$ graus de liberdade; Conc $=$ concentração; Bio = biofertilizante

Os resultados observados em Zea Mays L. pelo teste de Tukey $(\mathrm{p}<0,05)$, apresentou significância para CR entre os dois biofertilizantes na concentração de $150 \mathrm{~mL} \mathrm{~L}^{-1} \mathrm{e}$, entre as concentrações de biofertilizante bovino em Z. mays (Tabela 3). 
Tabela 3. Valores médios para porcentagem de germinação; comprimento da parte aérea (CPA) e de raiz (CR) de Zea mays L. (milho) submetidas as diferentes concentrações (0, 150, 300, 450, $600 \mathrm{~mL} . \mathrm{L}^{-1}$ ) de dois biofertilizantes.

\begin{tabular}{|c|c|c|c|c|c|c|}
\hline \multirow{2}{*}{$\begin{array}{c}\text { Concentração } \\
\text { mL.. }\end{array}$} & \multicolumn{2}{|c|}{ Germinação (\%) } & \multicolumn{2}{c|}{ CPA (mm) } & \multicolumn{2}{c|}{ CR (mm) } \\
\cline { 2 - 6 } & Bovino & Ovino & Bovino & Ovino & Bovino & Ovino \\
\hline 0 & $90,74^{\mathrm{aA}}$ & $85,18^{\mathrm{aA}}$ & $1,27^{\mathrm{aA}}$ & $1,22^{\mathrm{aA}}$ & $6,53^{\mathrm{ab}}$ & $4,37^{\mathrm{aA}}$ \\
\hline 150 & $96,29^{\mathrm{aA}}$ & $88,88^{\mathrm{aA}}$ & $1,58^{\mathrm{aA}}$ & $1,03^{\mathrm{aA}}$ & $8,47^{\mathrm{aA}}$ & $4,61^{\mathrm{aB}}$ \\
\hline 300 & $92,59^{\mathrm{aA}}$ & $98,14^{\mathrm{aA}}$ & $1,01^{\mathrm{aA}}$ & $1,01^{\mathrm{aA}}$ & $4,12^{\mathrm{bA}}$ & $3,98^{\mathrm{aA}}$ \\
\hline 450 & $96,29^{\mathrm{aA}}$ & $94,44^{\mathrm{aA}}$ & $0,49^{\mathrm{aA}}$ & $0,84^{\mathrm{aA}}$ & $4,92^{\mathrm{abA}}$ & $4,47^{\mathrm{aA}}$ \\
\hline 600 & $90,74^{\mathrm{aA}}$ & $96,29^{\mathrm{aA}}$ & $0,76^{\mathrm{aA}}$ & $0,86^{\mathrm{aA}}$ & $5,98^{\mathrm{abA}}$ & $4,10^{\mathrm{aA}}$ \\
\hline
\end{tabular}

Médias seguidas de letras iguais, minúsculas nas colunas e maiúsculas nas linhas, não diferem entre si pelo teste de Tukey a $5 \%$ de probabilidade.

Valores referentes ao CR, a maior média $(8,47 \mathrm{~mm})$ foi observada na concentração de $150 \mathrm{~mL} \mathrm{~L}^{-1}$ no biofertilizante bovino. Os resultados sugestionam que o biofertilizante bovino acarretou num aumento de $46 \%$ nessa variável em comparação ao biofertilizante ovino. Validando a hipótese de que o biofertilizante bovino teve sua mineralização mais rápida e, consequentemente, maior disponibilização do nitrogênio e que a decomposição do biofertilizante ovino foi mais lenta, devido a sua estrutura ser mais enrijecida (Almeida et al., 2017).

Em um estudo semelhante, aplicando o biofertilizante bovino em solo foi observado o aumento da massa seca de raiz e parte aérea de milho quando submetida as doses de 100 e $125 \%$, evidenciando o potencial de utilização do biofertilizante no cultivo em solo (Rebouças Neto et al., 2016).

O biofertilizante bovino vêm sido bastante discutido em vários trabalhos. Santos et al. (2019) verificou aumento de diâmetro e comprimento nos frutos de morangueiro na dose de $1250 \mathrm{~mL}$ por semana. Lima et al. (2018) cita o incremento na biomassa da parte aérea e total de morangueiro, ressaltando que o biofertilizante apresenta como excelente fonte nutricional. Aguiar et al. (2017), utilizou o biofertilizante bovino na irrigação de plantas de maracujazeiro e constatou o aumento no número de frutos e produção por planta.

De modo geral, os biofertilizantes não interferiram na germinação das sementes de Z. mays, foi observada uma média da porcentagem variando de $90 \%$ a $96 \%$ no bovino e $85 \%$ a $96 \%$ no ovino, os valores estão de acordo com o recomendado para a cultura em testes de vigor de sementes (Sbrussi e Zucareli, 2014). Resultados semelhantes foram observados por Barszcz et al. (2019) realizando teste ecotoxicológico com alface, onde, não observou diferença significativa durante a germinação utilizando efluente doméstico.

Nascentes et al. (2019) constatou diferença significativa no comprimento de raiz primária, em sementes de milho expostas às misturas biotratadas de aterro sanitário.

Em Phaseolus vulgaris L. nota-se diferença significativa pelo teste de Tukey $(\mathrm{p}<0,05)$ para a variável porcentagem de germinação entre os biofertilizantes na concentração de $600 \mathrm{~mL} \mathrm{~L}^{-1}$ e, entre as concentrações no biofertilizante ovino (Tabela 4).

Alguns autores mencionam a inibição da germinação e crescimento das raízes em bioensaios de germinação. Franco et al. (2017) avaliando a germinação das sementes de alface e pepino utilizando lixiviado de aterro sanitário bruto (chorume) verificaram efeito negativo na germinação das sementes. Thode Filho et al. (2019) verificou efeito fitotóxico na germinação das sementes e o crescimento radicular de alface utilizando extrato de bagaço de cana de açúcar residual. 
Tabela 4. Valores médios para porcentagem de germinação; comprimento da parte aérea (CPA) e de raiz (CR) de Phaseolus vulgaris L. (feijão) submetidas as diferentes concentrações (0, 150, 300, 450, 600 mL.L $\mathrm{L}^{-1}$ ) de dois biofertilizantes.

\begin{tabular}{|c|c|c|c|c|c|c|}
\hline \multirow{2}{*}{$\begin{array}{c}\text { Concentração } \\
\text { mL.. }^{-1}\end{array}$} & \multicolumn{2}{|c|}{ Germinação (\%) } & \multicolumn{2}{c|}{ CPA (mm) } & \multicolumn{2}{c|}{ CR (mm) } \\
\cline { 2 - 6 } & Bovino & Ovino & Bovino & Ovino & Bovino & Ovino \\
\hline 0 & $94,44^{\mathrm{aA}}$ & $85,18^{\mathrm{abA}}$ & $7,18^{\mathrm{aA}}$ & $2,62^{\mathrm{aA}}$ & $0,62^{\mathrm{aA}}$ & $0,85^{\mathrm{aA}}$ \\
\hline 150 & $74,07^{\mathrm{aA}}$ & $92,59^{\mathrm{aA}}$ & $3,44^{\mathrm{aA}}$ & $13,7^{\mathrm{aA}}$ & $0,22^{\mathrm{aA}}$ & $9,55^{\mathrm{aA}}$ \\
\hline 300 & $74,07^{\mathrm{aA}}$ & $88,89^{\mathrm{abA}}$ & $4,33^{\mathrm{aA}}$ & $17,14^{\mathrm{aA}}$ & $0,57^{\mathrm{aA}}$ & $17^{\mathrm{aA}} 14^{\mathrm{aA}}$ \\
\hline 450 & $81,48^{\mathrm{aA}}$ & $77,77^{\mathrm{abA}}$ & $6,02^{\mathrm{aA}}$ & $25,68^{\mathrm{aA}}$ & $0,23^{\mathrm{aA}}$ & $17^{\mathrm{aA}}$ \\
\hline 600 & $87,03^{\mathrm{aA}}$ & $57,41^{\mathrm{bB}}$ & $3,59^{\mathrm{aA}}$ & $34,50^{\mathrm{aA}}$ & $0,20^{\mathrm{aA}}$ & $40,32^{\mathrm{aA}}$ \\
\hline
\end{tabular}

Médias seguidas de letras iguais, minúsculas nas colunas e maiúsculas nas linhas, não diferem entre si pelo teste de Tukey a $5 \%$ de probabilidade.

Segundo alguns autores, os insumos orgânicos podem apresentar alta concentração de sais que é considerado um fator de estresse para os vegetais. No experimento realizado verificou-se alta condutividade elétrica no biofertilizante bovino (Tabela 1). É importante ressaltar que o biofertilizante foi aplicado no papel filtro, ou seja, em contato direto com as sementes. 0 aumento da concentração de sais pode promover a diminuição do potencial osmótico, dificultando a absorção de água, inibindo a germinação e, interferindo nos demais processos fisiológicos da planta. Visto que as espécies testadas nesse experimento são consideradas sensíveis a salinidade (Soares Filho et al., 2016).

Não foi observada a redução na porcentagem de germinação para ambas as espécies e nos dois biofertilizantes testados. Exceto na concentração de $600 \mathrm{~mL} \mathrm{~L}^{-1}$ no biofertilizante ovino nas plântulas de feijão. Os resultados corroboram com as observações de alguns autores que utilizaram biofertilizantes de origem animal. Martins et al. (2015), utilizando o dejeto bovino isolado ou como biofertilizante verificou efeitos benéficos nas plantas de feijão, recomendando seu uso como fertilizante. Bitencourt et al. (2020) descreve o aumento no crescimento de parte aérea de milho e feijão utilizando o biofertilizante bovino em solo.

Almeida et al. (2017) demonstrando a grande viabilidade da aplicação de biofertilizantes em alface, o autor concluiu que os dois estercos apresentam aptidão diferentes de decomposição e liberação de nutrientes, tendo o esterco oriundo de ovinos mais resistente a decomposição. Além de apresentar uma alta relação $\mathrm{C} / \mathrm{N}$, o nitrogênio e outros nutrientes presentes em esterco bovino são liberados gradativamente, contribuindo em aumentos significativos na cultura testada.

A partir dos resultados obtidos nas variáveis CPA e CR em P. vulgaris, as médias são estatisticamente semelhantes. Entretanto, ao avaliarmos isoladamente cada concentração com a dose controle, foi verificada uma média de 40,32 mm de CR e $34,50 \mathrm{~mm}$ de CPA na concentração de $600 \mathrm{~mL}^{-\mathrm{L}^{-1}}$ no biofertilizante ovino, relacionada ao controle é alta. As médias de CR e CPA em P. vulgaris sugerem que o biofertilizante ovino promoveu aumento nessas variáveis.

Com base nesse experimento, em condições de bioensaio de germinação por cinco dias, não foi possível verificar efeito positivo ou negativo aplicando os biofertilizantes nas culturas do feijão e do milho. Contudo, podemos ressaltar que não foi observado efeito tóxico sobre a germinação e o crescimento inicial das plântulas.

O ensaio de germinação é um teste preliminar que pode dar respostas de como os ecossistemas metabolizam, transformam, degradam, acumulam, eliminam ou sofrem a ação das diversas substâncias químicas neles introduzidas (Balan, 2017). Assim, avaliar os efeitos tóxicos sobre as plantas pode servir de base para a tomada de decisão da aplicação dos mesmos no solo com maior período de cultivo. 


\section{Conclusões}

Não foram verificados efeitos tóxicos dos biofertilizantes nas duas espécies avaliadas. 0 aumento no comprimento de raiz de milho foi verificado em ambos os biofertilizantes na concentração de $150 \mathrm{~mL} \mathrm{~L}^{-1}$. Entretanto, o bovino promoveu incremento de $46 \%$ nessa variável. A concentração de $600 \mathrm{~mL} \cdot \mathrm{L}^{-1}$ do biofertilizante bovino promoveu maior porcentagem de germinação de feijão comparado ao ovino.

\section{Conflito de interesses}

Os autores declaram não haver conflito de interesses.

\section{Referências}

Abreu, M. F.; Abreu Junior, C. H.; Silva, F. C.; Santos, G. C. G.; Andrade, J. C.; Gomes, T. F.; Coscione, A. R.; Andrade, C. A. Análises químicas de fertilizantes orgânicos (urbanos). In: Silva, F. C. Manual de análises químicas de solos, plantas e fertilizantes do solo. 2 ed. Brasília: Embrapa Informação Tecnológica, 2009. p. 309-481.

Aguiar, A. V. M.; Cavalcante, L. F.; Silva, R. M.; Dantas, T. A. G.; Santos, E. C. Effect of biofertilization on yellow passion fruit production and fruit quality. Revista Caatinga, v. 30, n. 1, p. 136-148, 2017. https://doi.org/10.1590/1983-21252017v30n115rc

Alencar, T. L.; Chaves, A. F.; Santos, C. L. A.; Assis Júnior, R. N.; Mota, J. C. A. Atributos físicos de um Cambissolo cultivado e tratado com biofertilizante na Chapada do Apodi. Revista Brasileira de Ciência do Solo, v. 39, n. 3, p. 737-749, 2015.

Almeida, I. I.; Sobreira, A. E. A.; Furtado, R. M.; Rodrigues, A. M. G.; Fernandes, J. N. V.; Fernandes, C. N. V. Produtividade da alface sobre efeito residual de doses e tipos de biofertilizantes. Anais do Congresso Brasileiro de Gestão Ambiental e Sustentabilidade Congestas 2017, v. 5 , p.587-596, 2017. Disponível em: <http://eventos.ecogestaobrasil.net/congestas2017/trabalhos/pdf/congestas2017-et-03027.pdf>. Acesso em: 22 dez. 2020.

Balan, D. S. L. Corantes naturais de aplicação têxtil: avaliação preliminar da toxicidade de urucum Bixa orellana L. (Malvales: Bixaceae) e hibisco Hibiscus sabdariffa L. (Malvales: Malvaceae). Revista Brasileira de Gestão Ambiental e Sustentabilidade, v. 4, n. 7, p. 151-157, 2017. https://doi.org/10.21438/rbgas.040715

Barszcz, L. B.; Bellato, F. C.; Benassi, R. F.; Matheus, D. R. Avaliação ecotoxicológica de efluentes tratados por alagados construídos. Engenharia e Sanitária Ambiental, v. 24, n. 6, p. 1147-1156, 2019. https://doi.org/10.1590/S1413-41522019184120

Bitencourt, G. A.; Vaso, L. M.; Gomez, A. L. C.; Souza, T. T.; Pradebon, B. S.; Montanhez, B. E. Ecotoxicologia de biofertilizante bovino e ovino. Fórum Ambiental da Alta Paulista, v. 16, n. 3, p. 96-107, 2020. https://doi.org/10.17271/1980082716320202388

Brasil. Resolução CONAMA no 375, de 29 de agosto de 2006. Define critérios e procedimentos, para o uso agrícola de lodos de esgoto gerados em estações de tratamento de esgoto sanitário e seus produtos derivados, e dá outras providências. Disponível em: <http://www2.mma.gov.br/port/conama/res/res06/res37506.pdf>. Acesso em: $22 \mathrm{dez}$. 2020. 
Brasil. Resolução CONAMA no 430, de 13 de maio de 2011. Dispõe sobre as condições e padrões de lançamento de efluentes, complementa e altera a Resolução no 357, de 17 de março de 2005, do Conselho Nacional do Meio Ambiente-CONAMA. Disponível em: <http://www2.mma.gov.br/port/conama/legiabre.cfm?codlegi=646>. Acesso em: $22 \mathrm{dez}$. 2020.

Brito, P. S. L.; Beckmann-Cavalcante, M. Z.; Amaral, G. C.; Silva, A. A.; Avelino, R. C. Reutilização de resíduos regionais como substratos na produção de mudas de cultivares de alface a partir de sementes com e sem peletização. Revista de la Facultad de Agronomía, v. 116, n. 1, p. 51-61, 2017.

EMBRAPA - Empresa Brasileira de Pesquisa Agropecuária. Manual de métodos de análise de solo. rev. atual. Rio de Janeiro: EMBRAPA, Centro Nacional de Pesquisas de Solos, 1997. v. 2. (Documentos, 1).

Ferreira, D. F. SISVAR: A computer analysis system to fixed effects split plot type designs. Revista Brasileira de Biometria, v. 37, n. 4, p. 529-535, 2019.

Franco, H. A.; Martins, G. M. de O.; Mussel, Y. L.; Moreno, S. C.; Thode Filho, S.; Marques, M. R. C. Ecotoxicidade de lixiviado de aterro sanitário na germinação de sementes de alface (Lactuca sativa L.) e pepino (Cucumis sativus L.). Revista de Estudos Ambientais, v. 19, n. 1, p. 36-43, 2017. https://doi.org/10.7867/1983-1501.2017v19n1p36-43

ISO - International Organization for Standardization. ISO 1269-2: Qualidade do solo determinação dos efeitos de poluentes na flora terrestre. 2 ed. Rio de Janeiro: ISO, 2014.

Lima, F. A.; Viana, T. V. A.; Sousa, G. G.; Correira, L. F. M.; Azevedo, B. M. Yield of strawberry crops under different irrigation levels and biofertilizer doses. Revista Ciência Agronômica, v. 49, n. 3, p. 381-388, 2018. https://doi.org/10.5935/1806-6690.20180043

Martins, J. D. L.; Moura, M. F.; Oliveira, J. P. F.; Oliveira, M.; Galindo, C. A. F. M. Esterco bovino, biofertilizante, inoculante e combinações no desempenho produtivo do feijão comum. Revista Agro@mbiente, v. 9, n. 4, p. 369-376, 2015. https://doi.org/10.18227/ 1982-8470ragro.v9i4.2583

Matos, C. C.; Mendes, A. D. R.; Colen, F.; Santos, L. D. T. Figueiredo, L. S.; Martins, E. R. Potencial fitotóxico do biofertilizante da casca de pequi (Caryocar brasiliense Comb.). Revista Cultura Agronômica, v. 27, n. 1, p. 160-172, 2018.

Miyazawa, M.; Pavan, M. A.; Muraoka, T.; Carmo, C. A. F. S.; Melo, W. J. Análise química de tecido vegetal. In: Silva, F. C. Manual de análises químicas de solos, plantas e fertilizantes do solo. 2. ed. Brasília: Embrapa Informação Tecnológica, 2009. p. 191-233.

Nascentes, A. L.; Pereira, B. C.; Pinho, C. F.; Silva, L. D. B.; Zonta, E.; Ferreira, J. A.; Campos, J. C. Avaliação da toxicidade de lixiviado de aterro sanitário utilizando germinação de sementes de milho. Revista de Estudos Ambientais, v. 21, n. 2, p. 20-30, 2019. https://doi.org/10.7867/1983-1501.2019v21n2p20-30

Rebouças Neto, M. O.; Leite, D. N. P.; Campos, J. R.; Veras, C. L.; Souza, I. R.; Monteiro Filho, L. R. Crescimento inicial do milho sob diferentes concentrações de biofertilizante bovino. Cadernos Cajuína, v. 1, n. 3, p. 4-14, 2016.

Sá, F. V. S.; Mesquita, E. F.; Bertino, A. M. P.; Costa, J. D.; Araújo, J. L. Influência do gesso e biofertilizante nos atributos químicos de um solo salino-sódico e no crescimento inicial do girassol. Irriga, v. 20, n. 1, p. 46-59, 2015. https://doi.org/10.15809/irriga.2015v20n1p46 
Santos, E. M.; Viana, T. V. A.; Sousa, G. G.; Azevedo, B. M.; Moraes, J. G. L. Yield and quality of strawberry fruits fertilized with bovine biofertilizer. Revista Caatinga, v. 32, n. 1, p. 16-26, 2019. https://doi.org/10.1590/1983-21252019v32n103rc

Sbrussi, C. A. G.; Zucareli, C. Germinação de sementes de milho com diferentes níveis de vigor em resposta à diferentes temperaturas. Semina: Ciências Agrárias, v. 35, n. 1, p. 215-226, 2014. https://doi.org/10.5433/1679-0359.2014v35n1p215

Silva, F. C.; Abreu, M. F.; Perez, D. V.; Eira, P. A.; Abreu, C. A.; Raij, B. V.; Gianelllo, C.; Coelho, A. M.; Quaggio, J. A.; Tedesco, M. J.; Silva, C. A.; Barreto, W. O. Métodos de análises químicas para a avaliação da fertilidade do solo. In: Silva, F. C. Manual de análises químicas de solos, plantas e fertilizantes do solo. 2. ed. Brasília: Embrapa Informação Tecnológica, 2009. p. 130-134.

Silva, R. B.; Sousa, C. P.; Zonta, E.; Nascentes, A. L.; Silva, L. D. B. Avaliação da toxicidade de água residuária de bovinocultura (ARB) utilizando germinação de sementes de milho (Zea mays L.). Anais do 28을 Congresso Brasileiro de Engenharia Sanitária e Ambiental, Rio de Janeiro, p. 1-7, 2015.

Soares Filho, W. S.; Gheyi, H. R.; Brito, M. E. B.; Nobre, R. G.; Fernandes, P. D.; Miranda, R. S. Melhoramento genético e seleção de cultivares tolerantes à salinidade. In: Gheyi, H. R.; Dias, N. S.; Lacerda, C. F.; Gomes Filho, E. Manejo da salinidade na agricultura: estudos básicos e aplicados. Fortaleza: Instituto Nacional de Ciência e Tecnologia em Salinidade, 2016. p. 259-274.

Soares, J. B.; Maia, A. C. F. Água: microbiologia e tratamento. Fortaleza: UFC, 1999.

Thode Filho, S.; Paixão, C. P. S.; Maranhão, F. S.; Franco, H. A. Avaliação ecotoxicológica do extrato solubilizado de bagaço de cana-de-açúcar residual via germinação de sementes de alface (Lactuca sativa L.). Revista de Estudos Ambientais, v. 21, n. 1, p. 46-55, 2019. https://doi.org/10.7867/1983-1501.2019v21n1p46-55 